2. Ganoza CA, Matthias MA, Saito M, Cespedes M, Gotuzzo E, Vinetz JM. Asymptomatic renal colonization of humans in the peruvian Amazon by Leptospira. PLoS Negl Trop Dis. 2010;4(2):e612. Epub 2010/02/27. pmid:20186328; PubMed Central PMCID: PMC2826405.

3. Adler B, Faine S. The antibodies involved in the human immune response to leptospiral infection. J Med Microbiol. 1978;11:387-400.

4. Romero EC, Caly CR, Yasuda PH. The persistence of leptospiral agglutinins titers in human sera diagnosed by the microscopic agglutination test. Rev Inst Med Trop São Paulo. 1998; $40: 183-184$.

5. Cumberland PC, Everard COR, Levett PN. Assessment of the efficacy of the IgM enzyme-linked immunosorbent assay (ELISA) and microscopic agglutination test (MAT) in the diagnosis of acute leptospirosis. Am J Trop Med Hyg. 1999;61:731-734.

6. Priyamvada L, Quicke KM, Hudson WH, Onlamoon N, Sewatanon J, Edupuganti $S$, et al. Human antibody responses after dengue virus infection are highly cross-reactive to Zika virus. Proc Natl Acad Sci U S A. 2016;113:7852-7. 10.1073/ pnas. 1607931113

Correspondencia: Stalin Vilcarromero.

Dirección: 141 Bergold Street, Brentwood, 11717, Nueva York, USA

Correo electrónico: stalinvil@gmail.com

\section{Escherichia coli PRODUCTOR DE BETALACTAMASAS DE ESPECTRO EXTENDIDO EN POLLOS PARA CONSUMO HUMANO}

\section{EXTENDED-SPECTRUM BETA LACTAMASE- PRODUCING Escherichia coli IN CHICKEN FOR HUMAN CONSUMPTION}

\author{
Lady Esther Huamán-Chacón 1,a, \\ Edgar Gonzales-Escalante 2,a
}

Sr. Editor. Durante años, la investigación sobre resistencia bacteriana estuvo centrada en bacterias aisladas de infecciones en humanos, en la actualidad existe gran interés por el estudio de bacterias de diferentes ecosistemas

\footnotetext{
1 Facultad de Tecnología Médica, Universidad Nacional Federico Villarreal. Lima, Perú.

2 Centro de Investigaciones Tecnológicas, Biomédicas y Medioambientales CITBM, Universidad Nacional Mayor de San Marcos. Lima, Perú.

a Tecnólogo médico

Recibido:30/09/2018 Aprobado: 27/03/2019 En línea: 28/06/2019
}

Citar como: Huamán-Chacón LE, Gonzales Escalante E. Escherichia coli productor de betalactamasas de espectro extendido en pollos para consumo humano. Rev Peru Med Exp Salud Publica. 2019;36(2):361-2. doi: http://dx.doi. org/10.17843/rpmesp.2019.362.3959. (animal, humano, alimentario, ambiente); estudiándose principalmente Escherichia coli y Enterococcus spp. por ser representantes de dos grupos bacterianos, los Gram negativos (GN) y Gram positivos (1).

Uno de los mecanismos de resistencia involucrado en GN es la producción de betalactamasas de espectro extendido (BLEE), que genera resistencia a muchos de los antibióticos betalactámicos de uso común, las cuales son transmitidas a través de plásmidos. Se ha descrito que un medio idóneo para que esta transmisión ocurra es la microbiota intestinal de humanos y animales, debido a que los antibióticos utilizados en el ámbito clínico y/o veterinario pueden ser excretados por vía entérica, estableciéndose de esta manera la presión selectiva a nivel intestinal, teniendo una gran importancia epidemiológica y evolutiva ${ }^{(2)}$.

Se ha considerado que ciertos alimentos de origen animal, principalmente en relación a las aves de corral, podrían ser fuente de transmisión de enzimas BLEE al hombre. Distintas publicaciones hacen referencia a la elevada presencia de Escherichia coli portadora de BLEE en las aves y principalmente en pollos ${ }^{(3-5)}$. Este aumento también se observa en aislamientos de origen clínico, lo que no necesariamente indica que exista una relación, pero evidencia que la resistencia bacteriana es un fenómeno global que está en aumento. El objetivo de este estudio fue determinar la presencia de Escherichia coli productora de BLEE en hisopado cloacal de pollos destinados al consumo humano.

Entre diciembre 2015 y abril 2016, se realizó el hisopado cloacal de 200 pollos vivos aparentemente sanos de dos centros de acopio de Lima, Perú. Para el aislamiento presuntivo de enterobacterias productoras de BLEE los hisopados se sembraron en agar MacConkey suplementado con $2 \mathrm{mg} / \mathrm{L}$ de cefotaxima, tomando una colonia lactosa positiva de aquellas placas donde hubo desarrollo, se identificaron por pruebas de bioquímica convencional, la detección fenotípica de BLEE se realizó mediante el método de sinergia del doble disco y la susceptibilidad antimicrobiana se determinó por el método de disco difusión de acuerdo a las recomendaciones del CLSI ${ }^{(6)}$. De los 200 hisopados cloacales, se detectaron 163 (85,5\%) Escherichia coli productoras de BLEE. El perfil de susceptibilidad se muestra en la figura 1.

Estudios con valores similares al presente reporte fueron hallados por Abreu et al ${ }^{(3)}$ en España, encontrando 86,6\% de Escherichia coli productora de BLEE. Así mismo Dierick et al, describieron un aumento de la prevalencia de Escherichia coli productora de BLEE en el tracto gastrointestinal de animales destinados al consumo, en especial pollos, pasando del 3\% en 2003 al 15\% en 2008 


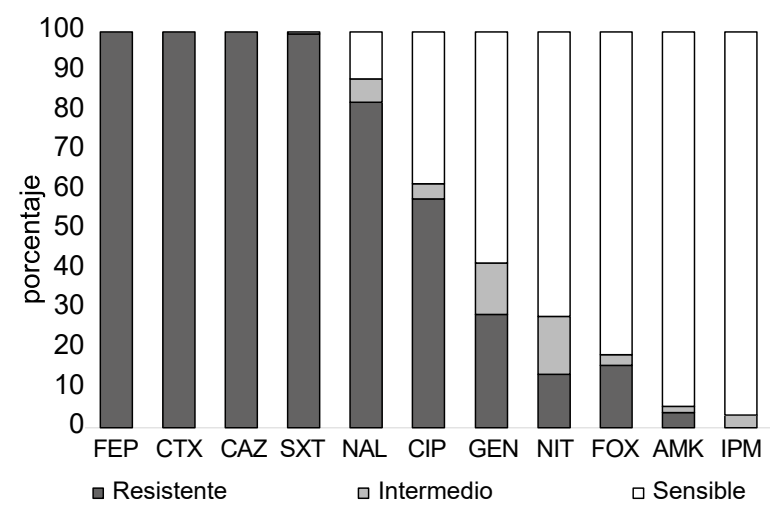

Figure 1. Perfiles de susceptibilidad antimicrobiana. NAL: ácido nalidixico, CIP: ciprofloxacina, AMK: amikacina, GEN: gentamicina, FEP: cefepime, CTX: cefotaxima, CAZ: ceftazidima, FOX: cefoxitina, IPM: imipenem, NIT: nitrofurantoina, SXT: trimetoprim/sulfametoxazol.

y $80 \%$ en 2009. ${ }^{(4)}$ En China, Yuan et al. encontraron $80 \%$ de Escherichia coli productora de BLEE ${ }^{(5)}$. Es importante precisar que los resultados pueden variar de acuerdo a la metodología usada para cada estudio, los métodos de producción utilizados y el lugar geográfico, ya que las BLEE no son homogéneas en todos los países.

En conclusión, reportamos el hallazgo de Escherichia coli productoras de BLEE en animales destinados al consumo humano, por lo que es necesario que se tomen medidas de control, ya que estos animales pueden actuar como reservorio de estos microorganismos a nivel comunitario.

Contribuciones de autoría: LEHC y EGE han participado en la idea de la investigación, concepción del artículo, la recolección de datos, material de estudio y redacción del artículo. Todos los autores aprobaron la versión final.

Fuentes de financiamiento: Autofinanciado.

\section{REFERENCIAS BIBLIOGRÁFICAS}

1. SommerMO,Dantas G, Church GM. Functional characterization of the antibiotic resistance reservoir in the human microbiota. Science, 2009; 325:1128-1131. doi: 10.1126/science.1176950.

2. Torres C, Zarazaga M. BLEE en animales y su importancia en la transmisión a humanos. Enferm Infecc Microbiol Clin 2007, 25(2) :29-37. doi: 10.1016/S0210-5705(09)71003-9

3. Abreu R, B. Castro-Hernández, Madueño A. Prevalencia de Enterobacterias productoras de ß-lactamasas de espectro extendido (BLEE), en exudados rectales de pollos de engorde en granjas avícolas en la isla de Tenerife, España Hig. Sanid. Ambient. 2013; 13(4):1091-1096.

4. Dierikx C, van der Goot J, Fabri T, van Essen- Zandbergen A, Smith H, Mevius D. Extended spectrum- $\beta$-lactamase and AmpC- $\beta$-lactamase producing Escherichia coli in Dutch broilers and broiler farmers. J Antimicrob Chemother 2013; 68:60-67. doi: 10.1093/jac/dks349.5. Yuan L, Liu JH, Hu
GZ, Pan YS, Liu ZM, Mo J, Wei YJ. Molecular characterizationof extended-spectrum beta-lactamase-producing Escherichia coli isolates from chickens in Henan Province, China.J Med Microbiol. 2009; 58:1449-1453. doi: 10.1099/jmm.0.012229-0.

6. Clinical and Laboratory Standard Institute. Performance standards for antimicrobial susceptibility testing. Twenty-six informational supplement M100-S28. Wayne, Pennsylvania: Clinical and Laboratory Standard Institute. 2018

Correspondencia: Edgar Gonzales Escalante

Dirección: Ca. José Santos Chocano 199 Ciudad Universitaria Bellavista - Callao

Correo electrónico:egones_5@hotmail.com

\section{Pneumocystis jirovecii EN PACIENTES CON VIH/SIDA EN UN HOSPITAL DE LIMA, PERÚ}

\section{Pneumocystis jirovecii DETECTION IN HIVIAIDS PATIENTS IN A HOSPITAL IN PERU}

\author{
Coralith García $a^{1,2, a, b}$, Theresa Ochoa ${ }^{1, b}$, Edgar Neyra ${ }^{3, c}$, \\ Jimmy Camargo $0^{1, d}$, Fiorela Alvarez ${ }^{1, d}$, \\ Beatriz Bustamante ${ }^{1,2, d}$
}

Sr. Editor. Pneumocystis jirovecii es el hongo oportunista a nivel pulmonar más común en personas con VIH/sida. El diagnóstico se basa tradicionalmente en la identificación microscópica de los quistes y trofozoítos en secreciones respiratorias. Sin embargo, con la introducción de la Reacción en Cadena de la Polimerasa (PCR) anidada el diagnóstico puede hacerse incluso en secreciones respiratorias obtenidas por métodos no invasivos ${ }^{(1)}$. La PCR anidada en el caso de Pneumocystis amplifica el ADN mitocondrial a través de la detección del gen mtLSU rRNA que es una región altamente conservada. Esta es una prueba altamente sensible y reproducible pudiendo ser usada en diferentes muestras biológicas ${ }^{(2)}$.

\footnotetext{
1 Instituto de Medicina Tropical Alexander von Humboldt, Universidad Peruana Cayetano Heredia. Lima, Perú.

Hospital Cayetano Heredia. Lima, Perú.

3 Facultad de Medicina, Universidad Peruana Cayetano Heredia. Lima, Perú

a $\mathrm{PhD}$ en Ciencias Biomédicas; ${ }^{\mathrm{b}}$ Médico Pediatra, especialista en Infectología Pediátrica, Magister en Medicina; ${ }^{\mathrm{c}}$ Biólogo, Magister en Bioquímica; ${ }^{\mathrm{d}}$ Médico Cirujano, Especialista en Enfermedades Infecciosas y Medicina Tropical Los resultados fueron presentados por Camargo J, Bustamante B, Neyra E, Ochoa T, Alvarez F, García C. Pneumocystis jiroveci Detection by Nested PCR in HIV-Infected Peruvian Patients. En IDWeek 2018, San Francisco, USA. Modalidad: Poster (\#2049). Recibido: 03/12/2018 Aprobado: 13/03/2019 En línea: 28/06/2019
}

Citar como: García C, Ochoa T, Neyra E, Camargo J, Alvarez F, Bustamante B. Pneumocystis jirovecii en pacientes con VIH/sida en un hospital de Lima, Perú. Rev Peru Med Exp Salud Publica. 2019;36(2):362-4. doi: http://dx.doi. org/10.17843/rpmesp.2019.362.4625. 